SUPPORTING INFORMATION

Fabrication and characterization of a novel herbicide delivery system with magnetic collectability and its phytotoxic effect on photosystem II of aquatic macrophyte

\author{
Mariana M. L. Forini ${ }^{\dagger}$, Débora R. Antunes ${ }^{\dagger}$, Luiz A. F. Cavalcante ${ }^{*}$, Montcharles S. Pontes ${ }^{*}$, \\ Érica R. Biscalchim ${ }^{\dagger}$, Alex O. Sanches ${ }^{\dagger}$, Etenaldo F. Santiago ${ }^{\ddagger}$, Leonardo F. Fraceto ${ }^{\ddagger}$ and \\ Renato Grillo ${ }^{*^{*}}$
}

† São Paulo State University (UNESP), Department of Physics and Chemistry, School of Engineering, Ilha Solteira, SP, 15385-000, Brazil.

$¥$ Natural Resources Program, Center for Natural Resources Studies (CERNA), Mato Grosso do Sul State University (UEMS), Dourados, Mato Grosso do Sul, 79804-970, Brazil.

${ }^{¥}$ São Paulo State University (UNESP), Department of Environmental Engineering, Institute of Science and Technology (ICTS), Sorocaba, SP, 18087-180, Brazil.

*Corresponding author:

Renato Grillo - São Paulo State University, Ilha Solteira, SP, Brazil

Phone: +55 1837431074

Email: renato.grillo@unesp.br or renato.grillo@ymail.com 


\section{Synthesis of iron oxide nanoparticles $\left(\mathrm{Fe}_{3} \mathrm{O}_{4} @ \mathrm{OA} \mathrm{NPs}\right)$}

Superparamagnetic iron oxide nanoparticles coated with oleic acid $\left(\mathrm{Fe}_{3} \mathrm{O}_{4} @ \mathrm{OA} \mathrm{NPs}\right)$ were prepared by the coprecipitation method using iron salts in alkaline medium according to Jadhav and colleagues (2013) ${ }^{I}$. For this, appropriate amounts of $\mathrm{FeCl}_{3} \cdot 6 \mathrm{H}_{2} \mathrm{O}$ and $\mathrm{FeCl}_{2} \cdot 4 \mathrm{H}_{2} \mathrm{O}$ were solubilized in an aqueous medium and subsequently added $30 \mathrm{~mL}$ of ammonium hydroxide $\left(\mathrm{NH}_{4} \mathrm{OH}\right)$ with stirring. Then, $2.5 \mathrm{~mL}$ of oleic acid were incorporated at the end of the synthesis and consecutive washes with water and hexane were performed. Finally, the nanoparticles were dried and dispersed in chloroform and stored in an amber flask at room temperature for later association with the polymeric microparticles.

\section{Physicochemical characterization of $\mathrm{Fe}_{3} \mathrm{O}_{4} @ \mathrm{OA}$}

$\mathrm{Fe}_{3} \mathrm{O}_{4} @ \mathrm{OA}$ NPs were characterized by X-ray diffractometry (XRD) to determine the crystallite size. For this, a Shimadzu XRD-6000 set at $45 \mathrm{kV}$ and $40 \mathrm{~mA}$ equipped with $\mathrm{Cu}$ $\mathrm{K} \alpha(\lambda=1.544 \AA)$ radiation was used. The measurements were performed in an angular range of $2 \theta=20$ to $80^{\circ}$ with a step size of $1 / \mathrm{min}$. The amount of oleic acid associated to nanoparticle surface was estimated using thermogravimetric measurements (TG/DTG). Measurements were carried out on an SDT Q-600 equipment (TA Instruments) using a heating rate of $10{ }^{\circ} \mathrm{C}$ in nitrogen atmosphere. $7 \mathrm{mg}$ of dry samples was used and platinum crucibles were utilized as a sample holder.

Figure 1S-A illustrates the diffraction spectra of the magnetic nanoparticles. It is possible to observe the presence of the diffraction peaks indexed to the planes (220), (311), (400), (422), (511) and (440) attributed to the inverse spinel type magnetite structure according to the Crystallographic Open Database (COD 96-900-2318). From the Scherrer equation (Eq.1) on assumption of the crystallites to be spherical as Prasad and colleagues $(2013)^{2}$, the crystallite size of the nanoparticles was determined, obtaining an average value $10.2 \mathrm{~nm}$. 


$$
\mathrm{D}=\frac{k \lambda}{\beta \cos \theta}
$$

Where $\beta$ represents full width at half maximum (FWHM) of reflection/plane (hkl).

Also, Figure 1S-B illustrates the mass loss curve (TG), as well as its respective derivative (DTG), for $\mathrm{Fe}_{3} \mathrm{O}_{4} @ \mathrm{OA}$ nanoparticles. From the DTG curve, it is possible to observe the presence of five distinct degradation peaks corresponding to five stages of mass loss in the TG curve: the first peak, centered around $80{ }^{\circ} \mathrm{C}$, whose percentage of mass loss was $0.8 \%$, was attributed to the removal of residual solvent, or even surface hydroxyl groups ${ }^{3}$. The second peak, centered at $242{ }^{\circ} \mathrm{C}$, with a mass loss of approximately $7.1 \%$, was attributed to the removal of free OA associated with the nanostructures surface. The third, centered at 350 ${ }^{\circ} \mathrm{C}$, with an associated mass loss of $9.5 \%$ was correlated to OA degradation directly bonded to the surface of the nanoparticles ${ }^{4}$. The values obtained for mass loss at such a stage, correlated to the high temperature value for it, confirm the presence of strong interaction between OA molecules and nanoparticles. The degradation of OA in different stages as noted, indicates the formation of a bilayer system between the components ${ }^{5}$. Finally, the fourth peak centered on $687^{\circ} \mathrm{C}$ was attributed to the phase transition from $\mathrm{Fe}_{3} \mathrm{O}_{4}$ to $\mathrm{FeO}$, corresponding to a mass loss of $5.5 \%$. While the fifth peak, located at $711{ }^{\circ} \mathrm{C}$, was related to the $\mathrm{FeO}$ deoxidation, since the TG/DTG analysis was performed under $\mathrm{N}_{2}$ atmosphere ${ }^{3}$. 

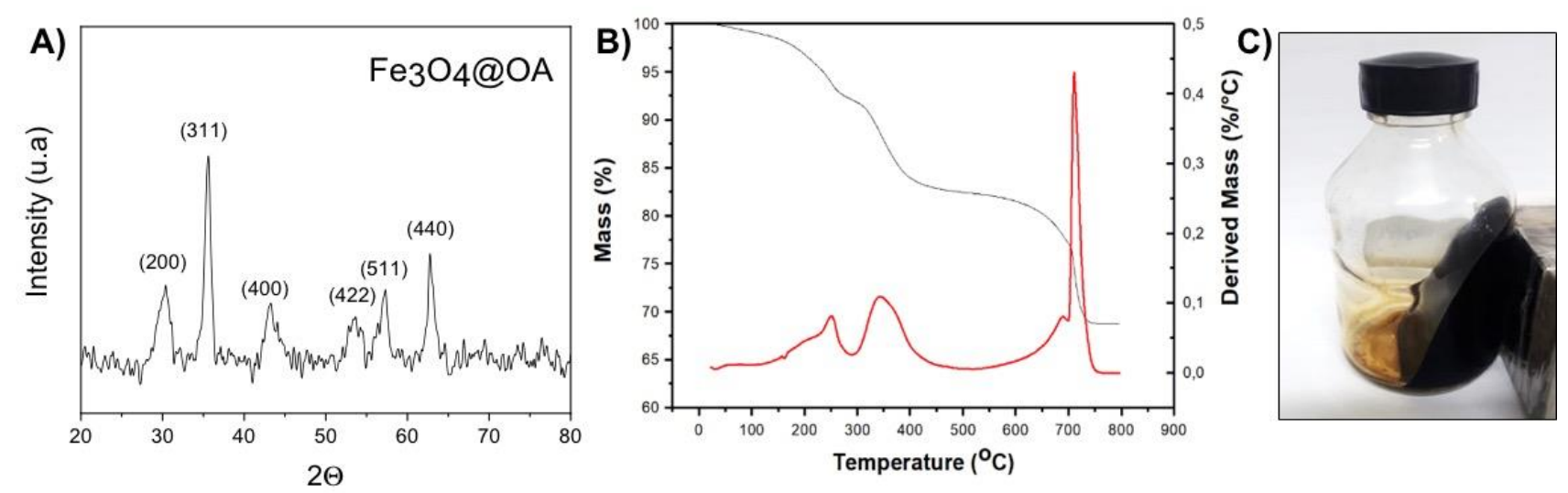

Figure 1S. Physicochemical characterization of $\mathrm{Fe}_{3} \mathrm{O}_{4} @ \mathrm{OA}$ nanoparticles: A) X-ray diffraction (XRD) analysis; B) Thermogravimetric analysis; and C) Image of the magnetic nanoformulation.

A)

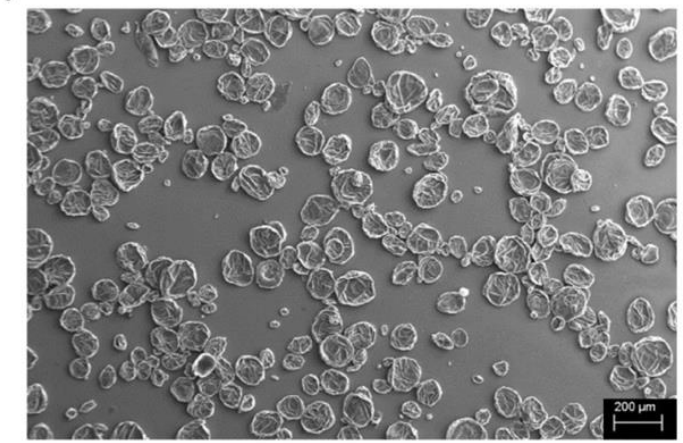

C)

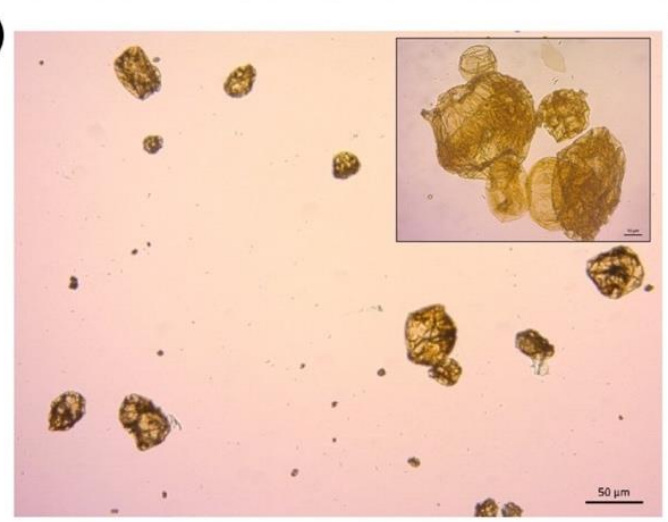

B)

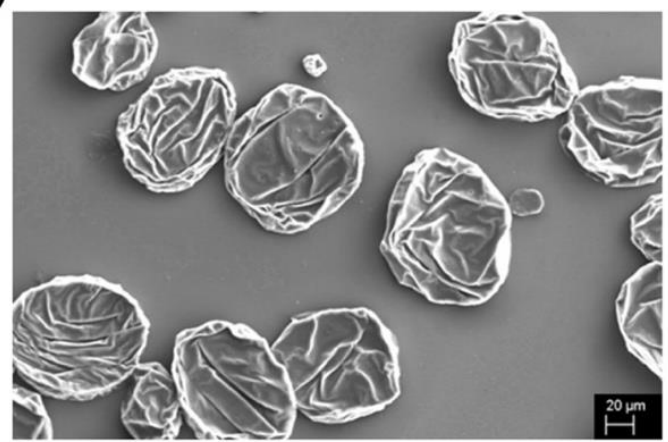

D)

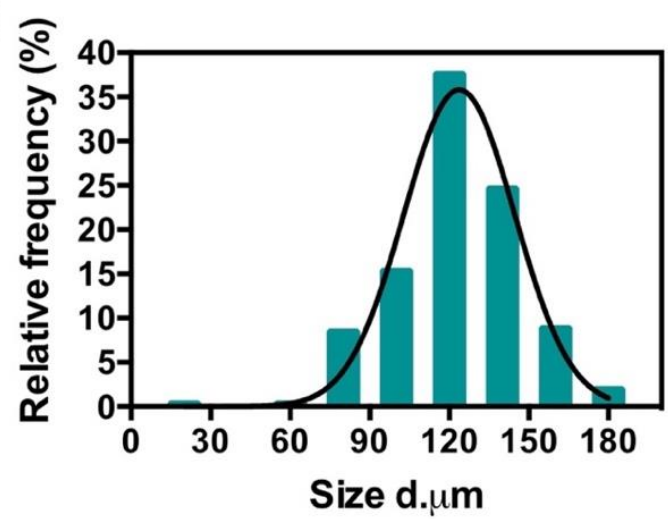

Figure 2S. Characterization of the PCL microparticles without the herbicide atrazine: A) Scanning Electron Microscopy (SEM) with 100x magnification, B) Scanning Electron Microscopy (SEM) with 500x magnification, C) Optical microscopy with 100x magnification (inset 400x magnification); and D) Relative frequency size distribution ( $\mathrm{n}=500$ particles). 

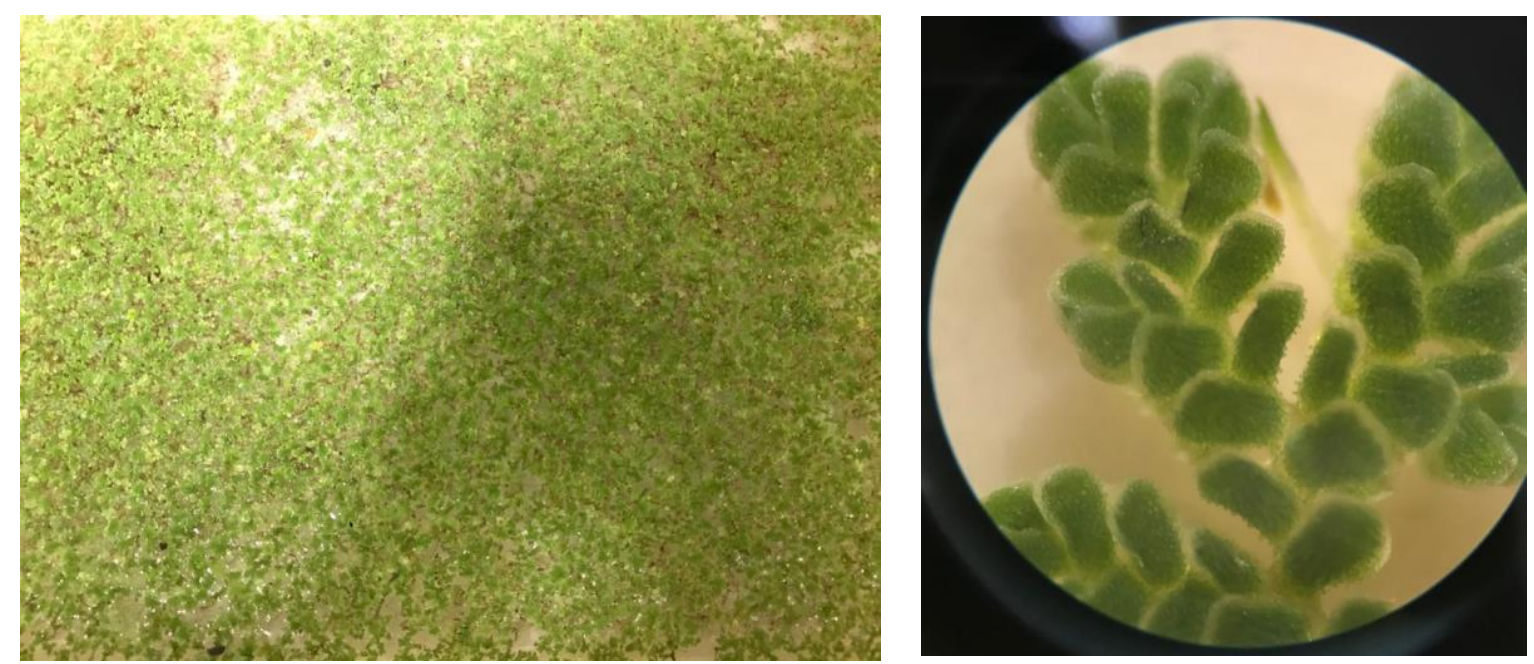

Figure 3S. Aquatic macrophyte (Azolla caroliniana) exposed to atrazine-loaded magnetic poly( $\varepsilon$-caprolactone) microparticles (MPs:ATZ).

Table 1S. Studies reporting the encapsulation efficiency of microparticles loading atrazine.

\begin{tabular}{ccccc}
\hline Microparticles & Herbicide & $\begin{array}{c}\text { Mean size } \\
(\boldsymbol{\mu m})\end{array}$ & $\begin{array}{c}\text { Encapsulation } \\
\text { efficiency }(\boldsymbol{\%})\end{array}$ & Reference \\
\hline PHBV/PVA & Atrazine & $6.57 \pm 3.10$ & 32.0 & Grillo et al. 2010 \\
PHBV/PVA & Atrazine & $24.0 \pm 0.1$ & $24.7 \pm 2.1$ & Lobo et al. 2011 \\
Organosolv lignin & Atrazine & $25.3 \pm 6.7$ & 77.5 & Taverna et al. 2018 \\
Lignin/Alginate & Atrazine & $50.0 \pm 3.0$ & $47.4 \pm 3.5$ & Bussato et al. 2019 \\
PCL & Atrazine & $\mathbf{6 0 - 9 0}$ & $\mathbf{6 9 . 3} \pm \mathbf{3 . 0}$ & This study \\
\hline
\end{tabular}

Video 1-S. Magnetic behavior of the atrazine-loaded magnetic poly( $\varepsilon$-caprolactone) microparticles (MPs:ATZ) when exposed by a neodymium magnet (50x50x24-N50).

\section{References}

1. Jadhav, N. V.; Prasad, A. I.; Kumar, A.; Mishra, R.; Dhara, S.; Babu, K. R.; Prajapat, C. L.; Misra, N. L.; Ningthoujam, R. S.; Pandey, B. N.; Vatsa, R. K., Synthesis of oleic acid functionalized $\mathrm{Fe} 3 \mathrm{O} 4$ magnetic nanoparticles and studying their interaction with tumor cells for potential hyperthermia applications. Colloid Surface B 2013, 108, 158-168. 
2. Prasad, A. I.; Parchur, A. K.; Juluri, R. R.; Jadhav, N.; Pandey, B. N.; Ningthoujam, R. S.; Vatsa, R. K., Bi-functional properties of Fe3O4@YPO4:Eu hybrid nanoparticles: hyperthermia application. Dalton T 2013, 42, 4885-4896.

3. Zhao, S. Y.; Lee, D. K.; Kim, C. W.; Cha, R. G.; Kim, Y. H.; Kang, Y. S., Synthesis of magnetic nanoparticles of $\mathrm{Fe} 3 \mathrm{O} 4$ and $\mathrm{CoFe} 2 \mathrm{O} 4$ and their surface modification by surfactant adsorption. B Korean Chem Soc 2006, 27, 237-242.

4. Mahdavi, M.; Bin Ahmad, M.; Haron, M. J.; Namvar, F.; Nadi, B.; Ab Rahman, M. Z.; Amin, J., Synthesis, Surface Modification and Characterisation of Biocompatible Magnetic Iron Oxide Nanoparticles for Biomedical Applications. Molecules 2013, 18, 7533 7548.

5. Shen, L. F.; Laibinis, P. E.; Hatton, T. A., Bilayer surfactant stabilized magnetic fluids: Synthesis and interactions at interfaces. Langmuir 1999, 15, 447-453. 